\title{
Functionalized Mesoporous Thin Films for Biotechnology
}

\author{
Barbara Sartori, Heinz Amenitsch and Benedetta Marmiroli *(D) \\ Institute of Inorganic Chemistry, Graz University of Technology, 8010 Graz, Austria; \\ barbara.sartori@tugraz.at (B.S.); heinz.amenitsch@tugraz.at (H.A.) \\ * Correspondence: benedetta.marmiroli@tugraz.at
}

Citation: Sartori, B.; Amenitsch, H.; Marmiroli, B. Functionalized Mesoporous Thin Films for Biotechnology. Micromachines 2021, 12, 740. https://doi.org/10.3390/mi 12070740

Academic Editors: Francesco Gentile and Gobind Das

Received: 2 June 2021

Accepted: 21 June 2021

Published: 24 June 2021

Publisher's Note: MDPI stays neutral with regard to jurisdictional claims in published maps and institutional affiliations.

Copyright: (c) 2021 by the authors. Licensee MDPI, Basel, Switzerland. This article is an open access article distributed under the terms and conditions of the Creative Commons Attribution (CC BY) license (https:// creativecommons.org/licenses/by/ $4.0 /)$.

\begin{abstract}
Mesoporous materials bear great potential for biotechnological applications due to their biocompatibility and versatility. Their high surface area and pore interconnection allow the immobilization of molecules and their subsequent controlled delivery. Modifications of the mesoporous material with the addition of different chemical species, make them particularly suitable for the production of bioactive coatings. Functionalized thin films of mesoporous silica and titania can be used as scaffolds with properties as diverse as promotion of cell growth, inhibition of biofilms formation, or development of sensors based on immobilized enzymes. The possibility to pattern them increase their appeal as they can be incorporated into devices and can be tailored both with respect to architecture and functionalization. In fact, selective surface manipulation is the ground for the fabrication of advanced micro devices that combine standard micro/nanofluids with functional materials. In this review, we will present the advantages of the functionalization of silica and titania mesoporous materials deposited in thin film. Different functional groups used to modify their properties will be summarized, as well as functionalization methods and some examples of applications of modified materials, thus giving an overview of the essential role of functionalization to improve the performance of such innovative materials.
\end{abstract}

Keywords: mesoporous thin films; silica; titania; functionalization; biotechnology; biomedicine

\section{Introduction}

Mesoporous materials inspired by nature have been developed in the past decades, being particularly attractive because they allow for functional design and applications [1,2]. By definition, mesoporous materials present interconnected pores with a diameter in the range of 2-50 nm, which are arranged in ordered or worm-like architecture. The pores' dimension, their arrangement, and their framework can be tuned changing the chemical composition. The whole surface can then be modified incorporating ions, functional groups or even molecules, that interact with the surface as well as with bulk material, changing its properties. In this perspective, ordered mesoporous materials play a leading role due to their versatility in terms of structural characteristics and possible applications [3]. In fact, the high surface-to-volume ratio and the interconnection of the pores, make them suitable for separation technologies, sensors, spatially defined materials for hosting cells [4], substances or reactions, or for fixation of biologically active species. More specifically, they are promising tools for biotechnology and biomedicine, in particular for in-situ treatment approaches. Recently, several studies demonstrated the multiple possibilities for biotechnological applications of mesoporous materials, thanks to their biocompatibility [5-7] and to their high surface area that makes them ideal vectors for drug delivery [8-10]. They also proved to be effective to accelerate hemostasis while preventing infections in wound sites [11].

Most of the works published so far presenting applications in biomedicine or biotechnology describe mesoporous materials in the form of nanoparticles. Nanoparticles are used because they can be injected on-site, their solubility and toxicity can be easily assessed with in vitro and in vivo tests, and they do not require to be deposited on any additional 
support which, in the case of biomedical applications, must be biocompatible and not lead to toxicity problems. Nevertheless, over the years both the emerging interest in the development of materials able to inhibit bacterial proliferation on surfaces such as surgical instruments, and the advantages of in-situ delivery of drugs or ions, for instance, to stimulate osteogenesis in the case of orthopaedic or dental implants, have been highlighted [12]. Mesoporous silica and titania coatings have proved to be promising appliances, since it is possible to deposit them as thin films even on irregular surfaces such as surgical screws [13]. Therefore they can be used in tissue engineering, taking advantage of their bioactivity: it was demonstrated that $\mathrm{SiOH}$ and $\mathrm{TiOH}$ groups on the surface of mesoporous silica and titania act as nucleation sites for the formation of apatite crystals when submerged in Simulated Body Fluid (SBF) [14,15], thus enhancing bone regeneration and cell growth This opens new routes to innovative applications in regenerative medicine, allowing local administration of drugs for the repair of tissues damaged by trauma or genetic diseases, as well as for the treatment of osteoporosis [16].

For the present review, we therefore decided to focus our attention on mesoporous silica and titania thin films. In fact, among mesoporous materials, $\mathrm{SiO}_{2}$ is one of the most used, biocompatible substrates: its well-known and tested synthesis methods, and its predictable dissolution in a fluid with physiological compatible characteristics, [17-19] make it an attractive substrate in biomedicine. On the other hand, $\mathrm{TiO}_{2}$ shows remarkable photocatalytic activity, making it a possible choice for sterilizing coatings [13,20].

In 1992, Kresge and coworkers reported the unprecedented synthesis of well-ordered mesoporous silica materials, the widely known MCM family [21]. Shortly, their discovery was followed by the one of Antonelli and Ying from the Massachusetts Institute of Technology (MIT), who reported in 1995 the synthesis of mesoporous titanium dioxide $\left(\mathrm{M}-\mathrm{TiO}_{2}\right)$ [22]. Since these pioneering works, strong efforts have been put to understand the chemistry of the condensation process, as well as developing applications that could take advantage of these innovative materials. The result is a number of different synthesis protocols and a deep understanding of how these materials can be modified, to tailor them to the desired function.

Mesoporous thin films can be prepared via different approaches [23-25]: the most commonly used is the sol-gel method [26,27], in which the self-assembly of the organometallic species is driven by the evaporation of the solvents and consequent condensation of the surfactant, in a process known as evaporation induced self-assembly (EISA) [28]. Templating strategies allow the synthesis of hierarchically ordered materials, and give the possibility to tune the mesopores' size and their architecture, which is a critical aspect when it comes to applications like drug delivery or surface coating. In the past few decades, several templating agents were used for the production of mesoporous material. Templating agents can be solids that act as structuring promoters for the inorganic solution and are then removed by heating, like dense or porous nanobeads [29-31]; alternatively, the inorganic framework condensation can be directed by the self-assembly of surfactant molecules or polymers. In this latter case, the inorganic precursor is added to a templating surfactant dissolved in a suitable solvent. Hierarchically oriented thin films are obtained from the sol-gel, which is deposited on the surface of the solid support (typically silicon or glass, but also metal alloys in case of biomedical coatings) via spray-, dip- or spin-coating. The mesostructure condenses at the evaporation of the solvents [32].

After synthesis, the film must be consolidated in order to remove the templating agent and stabilize the inorganic structure. The most commonly used consolidation process is calcination, at a temperature that typically ranges from $300{ }^{\circ} \mathrm{C}$ to $500{ }^{\circ} \mathrm{C}$ [33-37]. Other methods consist of the thermal treatment at low temperature followed by the extraction of the template with an adequate solvent $[38,39]$ or via $\mathrm{UV}^{-\mathrm{O}_{3}}$ processing [40]. Furthermore, top-down techniques like UV lithography [41-43], Electron Beam Lithography [44] and more recently X-ray irradiation $[36,45,46]$ allow both the consolidation and the patterning of the mesoporous structure, in order to enable the precise positioning of mesoporous areas on the substrate for the design and fabrication of novel kind of microdevices. 
As an alternative approach, homogeneous layers of mesoporous nanoparticles can be prepared: once produced via EISA, the consolidated, template free nanoparticles can be diluted in a suitable solvent to obtain a colloidal suspension that is spread on solid surfaces via doctor blading [32], dip coating [47], spin coating [48], or even used to grow mesoporous thin films directly on surfaces [49]. Uniform, smooth thin films of nanoparticles can be obtained via Matrix-Assisted Pulsed Laser Evaporation (MAPLE), which is a technique derived from Pulsed Laser Deposition [50]. In this approach, a low concentration solution of polymer or organic compound (the target) dispersed in an optically absorbing solvent is frozen and subsequently irradiated with a high energy pulsed laser beam: the rapid heating causes the fast evaporation of the solvent and the resulting target ablation process induces a uniform deposition of the solute on the support surface. As most of the incident laser energy is absorbed by the solvent, the solute deposition is a soft process that occurs without photochemical or thermal decomposition of organic molecules, thus allowing the deposition of thin, uniform and smooth films of, e.g., nanoparticles loaded with sensitive molecules [51].

Mesoporous coatings of $\mathrm{TiO}_{2}$ and $\mathrm{SiO}_{2}$ have been extensively studied as supports for bone tissue regeneration $[47,52,53]$, for controlled in situ drug release, $[54,55]$ or for applications in the field of orthopaedics and dental implants. It was demonstrated that the surface roughness improves eucariotic cell adhesion and growth [56], while at the same time, bacterial adhesion is reduced on mesoporous surfaces [57,58], making mesoporous coatings useful tools to prevent biofilm formation. Due to their photocatalytic activity, $\mathrm{TiO}_{2}$ mesoporous thin films can be used as self-sterilizing material for coating medical devices $[16,59]$ with no further modifications or molecules loading.

The anti-biofilm activity of silica is even more efficient when the mesopores are loaded with antibiotics or ions which have antibacterial properties like silver, magnesium or copper [60]. Surface functionalization can be later applied to immobilize further active molecules [61] and to change the mesoporous silica surface charge, which is related to cytotoxicity [62]. This brings forward the importance of functionalization. Functionalization is a process in which a surface is decorated by a molecule. Functionalizing the mesoporous surface, it is possible to tune its hydrophilicity/hydrophobicity [63,64], to protect the material from non-specific interactions with the surrounding environment $[65,66]$, or to avoid binding of non-specific molecules [67], tailoring the characteristics to the foreseen applications. Additionally, the properties of bulk material can be modified [68].

Despite the great potential of these materials in nanomedicine and biotechnology, only a few studies describe the possible exploitation of functionalized mesoporous thin films. In this review, we will try to fill this gap, outlining the role of functionalization of silica and titania mesoporous thin films with small functional groups, biological molecules or ions. In particular, we will focus on applications in the field of regenerative medicine and antimicrobial coatings.

\section{Functionalization Protocols}

Organic and inorganic groups, antimicrobial compounds [69], small biomolecules [70,71], or ions can be attached to mesoporous thin films, in order to change the material properties (Figure 1).

Functionalization can be obtained in different ways [52,65,72,73], the most common methods are co-condensation and post-grafting. In co-condensation the functionalizing group is added to the sol-gel solution and thus is distributed throughout the whole material bulk.

In post grafting, the functionalizing groups are attached to the mesoporous surface after the film consolidation (Figure 2).

The physiochemical interaction and the interface chemistry change depending on the selected approach. The choice of the method depends on many factors which are related to each other, for example, the compatibility of the functional molecules with the mesoporous material precursor solution, or the area where the functional elements have to be present and active. Therefore the functionalization strategy should be carefully designated [74]: the simple "one pot" co-condensation is limited by the fact that the functionalizing molecule 
must not interfere with the self-assembly of the mesostructure, and must be resistant to the synthesis conditions. Post grafting methods allow to bypass these limitations, and to obtain a more homogeneous distribution of the functionalizing species at the mesoporous surface, as demonstrated by Calvo and coworkers. They studied the difference between postgrafting functionalization and co-condensation during silica mesoporous film synthesis, finding that in the latter case, part of the functional groups are embedded in the matrix and are not accessible for subsequent reactions: thus, the number of available functional groups on the mesoporous surface is higher for post grafting functionalized materials [75]. On the other hand, post-synthesis functionalization is limited by the dimension and the architecture of the pores, as only molecules which are small enough can diffuse into the mesoporous matrix [76].

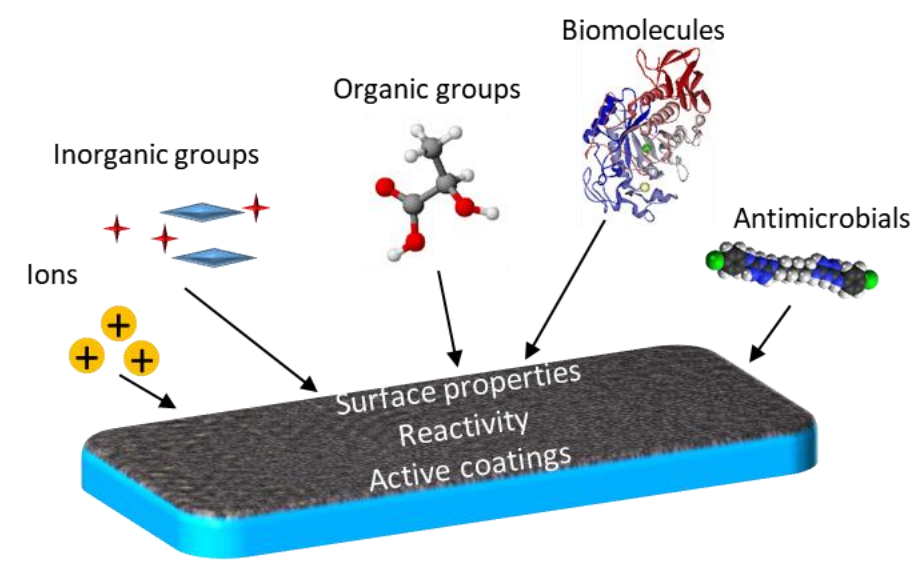

Figure 1. Schematic illustration of the various functionalization groups of mesoporous thin films.

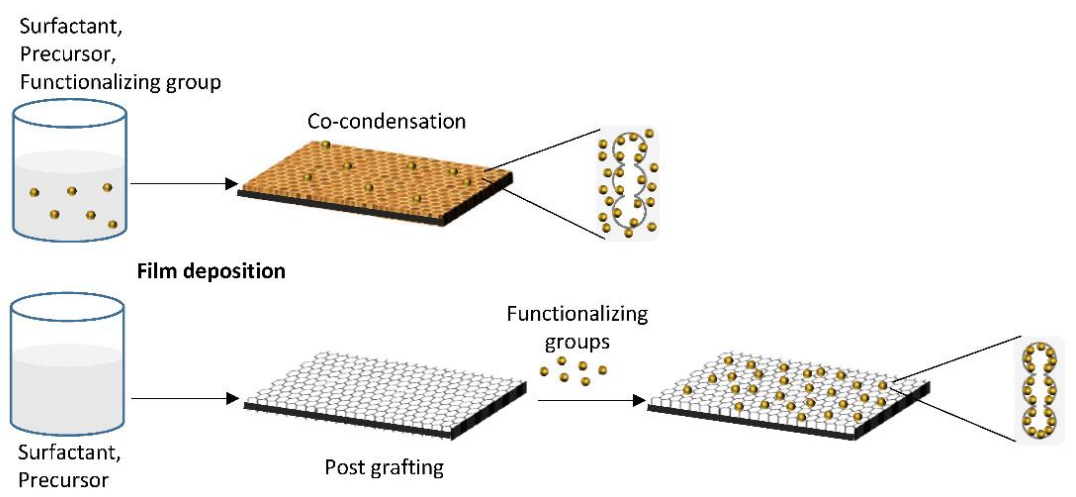

Figure 2. Schematic representation of mesoporous thin film functionalization. Post grafting (bottom) promotes the accessibility of more functional groups, with respect to co-condensation (top) where they are dispersed through the whole mesoporous matrix instead of the pores surface only.

As summarized recently by Tiemann and Weinberger [77], when different hierarchical surfaces of mesoporous materials are present, each of them can be selectively functionalized for applications in, e.g., sensing, cancer cell targeting, or drug delivery. For example, pores and surfaces can be protected with temporary ligands, or the dimension, reactivity and diffusion properties of the functionalizing agents can be used to selectively modify the material.

In the following, we will summarize some applications of functionalized silica and titania thin films, either produced via co-condensation or via post grafting. Functionalization with groups ranging from ions to biomolecules is described, aiming to emphasize the importance of surface modification of mesoporous materials for biotechnology and biomedicine.

Table 1 summarizes the main functional moieties presented in this review and their use for mesoporous silica and titania thin films. 
Table 1. Summary of the functionalization groups described in the text, grouped by activity or surface modification.

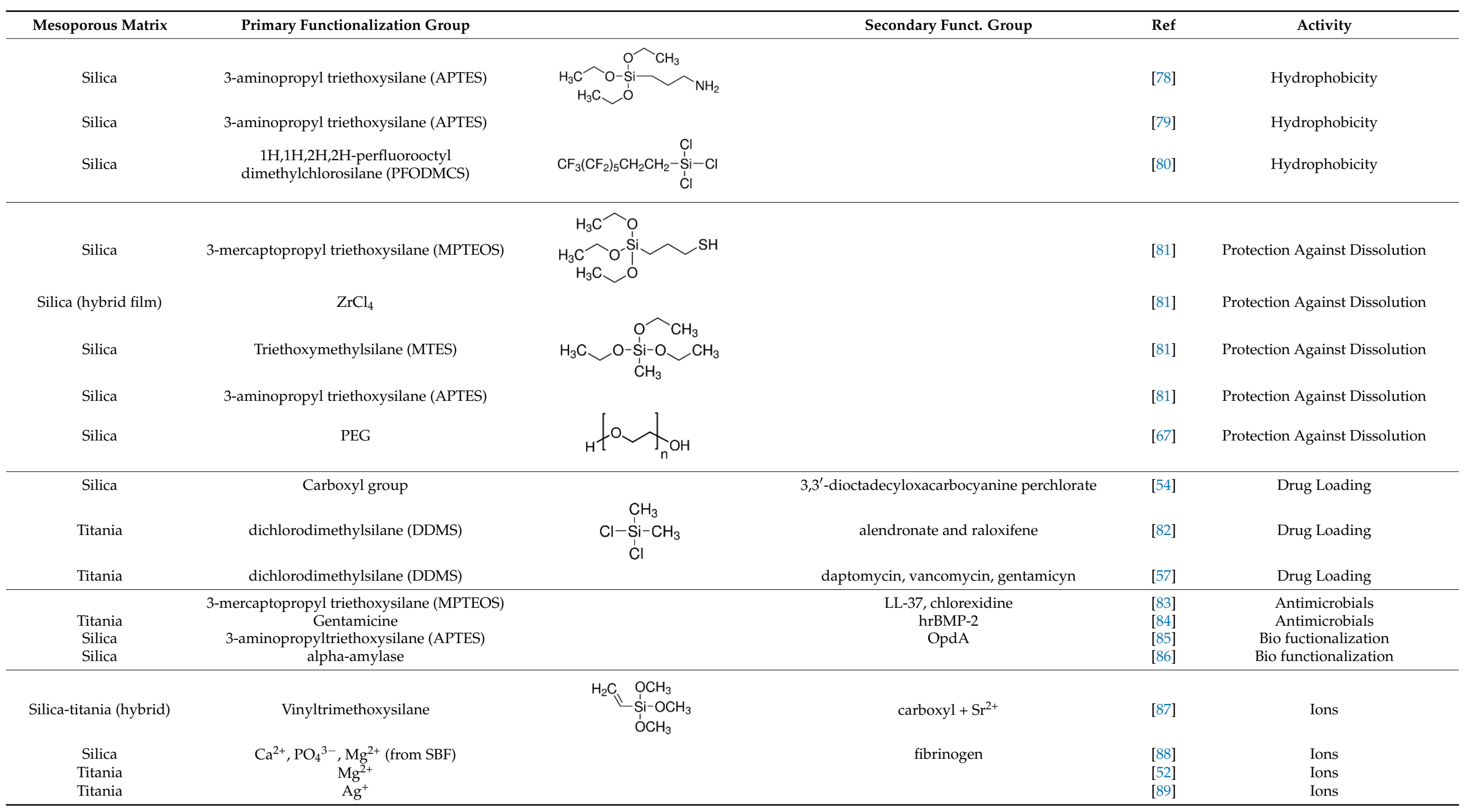




\section{Functional Groups}

Functional groups, that involve for instance carboxy, hydroxyl, amino and thiol groups, or organometallic species, can be used to change the surface properties of mesoporous materials (Table 1). Hybrid thin films materials can be produced grafting organic moieties to silica to favour specific interactions with bioactive molecules: mercaptopropylated silanes are used to functionalize the silica surface with thiol groups, making the surface ready for further functionalization with biological molecules such as peptides by the formation of disulfide bonds [79].

Silica mesoporous nanomaterial can be functionalized with organosilanes $\left[\mathrm{R}-\mathrm{Si}(\mathrm{OR})_{3}\right]$ via post-synthetic grafting, to modify the pore's inner surface with organic groups without affecting the mesostructure [90]. Organosilanes are used mainly to change the hydrophilic/hydrophobic character of the mesoporous surface with the addition of functional moieties such as amino- or carboxy-groups, which promote the subsequent adsorption of small molecules such as antimicrobials or enzymes, and prevent the degradation of material in physiological conditions.

In the following, we will report the properties modifications induced by functional groups, and some applications of the resulting mesoporous silica and titania thin films.

\subsection{Change of Hydrophilicity of the Surface}

A commonly used organosilane is APTES $\left[\mathrm{R}=\left(\mathrm{CH}_{2}\right)_{3} \mathrm{NH}_{2}\right]$, which functionalizes the mesoporous surface with amino groups that make the surface more hydrophobic, and can be used to attach other organic functional groups [91].

Marmiroli and coworkers investigated the possibility to hydrate lipid membranes deposited on mesoporous silica thin films, by conveying water through the mesopores due to a change of humidity of the environment. Mesoporous films were prepared using different surfactants and consolidation treatments: thermal treatment, $\mathrm{X}$-ray irradiation, and both [78].

Selected samples were functionalized by immersion in 1mM APTES solution in toluene, in a controlled atmosphere, for $12 \mathrm{~h}$. The authors aimed to modify the physical properties of the surface altering the hydrophilicity of the mesoporous material and thus, tuning the water release through the mesopores which is an important aspect for lab-on-chip applications. To demonstrate the effect of functionalization on the mesostructure water uptake, the phase transition of palmitoyl-2-oleoyl-sn-glycero-3-phosphocholine (POPC) in response to hydration was evaluated. POPC was deposited on the treated mesoporous material via drop-casting, and its phase transition was evaluated with Small Angle X-ray Scattering (SAXS) changing the environmental humidity in the controlled RH ramp from 15 to $75 \%$. For comparison, the same experiment was conducted on bare silicon wafer. The experiment results showed that lipids deposited on mesoporous material undergo hydration-driven phase transition at lower $\mathrm{RH}$ with respect to bare silicon, suggesting the possibility to feed water through the pores. APTES functionalized samples were less effective in conveying water to the deposited lipid, demonstrating that the functionalization with APTES reduces hydrophilicity of mesoporous materials and can be used to tailor the hydration through the pores.

Recently, the functionalization of silica mesoporous thin films to alter the wettability of the surface was obtained by vapor-phase deposition of $1 \mathrm{H}, 1 \mathrm{H}, 2 \mathrm{H}, 2 \mathrm{H}$-perfluorooctyl dimethylchlorosilane (PFODMCS) [80]. A controlled alteration of the wetting properties of mesoporous silica is useful for instance to regulate the flow of an aqueous solution in devices suitable for drug delivery. Khalil and coworkers demonstrated the possibility to tune the hydrophobicity of silica thin films produced via sol-gel EISA, changing the functionalization time. Evaluation of the surface hydrophobicity with contact angle and ellipsometry measurements, demonstrated that at a full hydrophobicity, the pores were not sterically blocked, thus they were still accessible for water loading. The access to the pores by redox molecules in acidic and alkaline conditions was also influenced by the degree 
of hydrophobicity of the pores, opening new sceneries for applications such as molecular separation devices and biosensors.

\subsection{Protection against Dissolution}

While titania thin films exhibit high chemical stability in biologically relevant conditions, silica thin films in aqueous environment are hydrolyzed and form silicilic acid or silicate species [19]. This progressive dissolution of the silica matrix promotes the release not only of the carried drug, but also of solubilized silica which might nucleate and accumulate randomly, posing a toxicity risk to the organism [81,92].

Functionalization with amino-groups [79,93] mercaptopropyl groups [83] or PEG [67] has also a protective effect against the dissolution of the mesoporous silica film. Fontecave and coworkers made an extensive study on the degradation of pure silica thin films in comparison with silica-zirconia, and hybrid thin films functionalized by grafting reactive alkoxysilane molecules to the mesoporous surface [81]. In an experiment performed submerging pure silica and zirconia-doped samples in PBS at biologically relevant temperatures, they demonstrated that the dissolution rate of doped silica thin film was slower than that of pure silica, and could be tuned adjusting the zirconia content. Hybrid thin films produced by co-condensation of small amounts of methylated (MTEOS) and mercaptopropyl (MPTEOS) silanes precursors showed lower dissolution rates as well, suggesting the stabilization of the $\mathrm{Si}-\mathrm{O}$ bond, and the protective effect of hydrophobic functionalization groups. They also demonstrated that the concentration of amino-functionalized groups on the surface, plays a role in reducing the dissolution rate of the silica matrix.

\subsection{Drug Loading}

Surface modifications or two-steps functionalization might be necessary to adsorb enzymes or hydrophobic drugs to the mesoporous matrix.

Björk and colleagues [54] produced mesoporous silica thin films from nanoparticles via direct growth method on silicon substrates pre-treated with octa-decyltrichlorosilane [94]: this approach has the advantage that it allows to grow thin films in 3D directions [49], without the need of a flat surface to produce the thin films, which is beneficial for surgical implants, e.g., The films were functionalized with $-\mathrm{COOH}$ groups soaking them in a $25 \%$ water solution of carboxyethylsilanetriol di-sodium salt, in order to increase its hydrophobicity. The $\mathrm{COOH}$-functionalization allowed loading the mesopores with $3,3^{\prime}$ dioctadecyloxacarbocyanine perchlorate ( $\mathrm{DiO})$, a small, yellow-fluorescent hydrophobic model drug. The amount of drug inserted and then released from the substrates was evaluated via UV-vis measurements before and after loading: the results showed that the intensity of the $\mathrm{DiO}$ signal at $503 \mathrm{~nm}$ after incubation was lowered by $15 \%$. The stability of the immobilized drug was evaluated with the same technique on the supernatant after $24 \mathrm{~h}$ incubation in cell growth medium (DMEM + FCS 10\%): in this case, no UV-vis signal was detected in the supernatant, confirming that the adsorbed $\mathrm{DiO}$ remained into the pores.

Confocal laser scanning microscopy was used to investigate the drug uptake by murine myoblast muscle cells. $\mathrm{C} 2 \mathrm{C} 12$ cells grown on the drug-loaded mesoporous film were able to incorporate the film's nanoparticles: once absorbed, these slowly released their drug content in the cell, as evidenced by the detectable intracellular $\mathrm{DiO}$ fluorescence after $4 \mathrm{~h}$, and increased after $24 \mathrm{~h}$ of incubation.

A further experiment was performed, labelling the mesoporous nanoparticles with ATTO647N red-emitting fluorescent dye before loading them with a five-times reduced amount of DiO: this allowed to visualize clearly the fluorescence signal from both labelled silica and from the model drug $\mathrm{DiO}$, thus confirming the uptake of the particles by the cells after 8 and 24 h of cells incubation.

Therapeutic molecules can be administered via mesoporous $\mathrm{TiO}_{2}$ thin films when a long-term, slow local drug release is desired, as in the case of bone-implant integration. EISA process allows the production of mesoporous film on non-flat surfaces, which is a great advantage for coating surgical devices. Harmankaya and colleagues performed 
an in-vivo study of the integration of mesoporous coated implants into the bone [82]. Osteoporosis drugs Alendronate (ALN) and Raloxifene (RLX) were immobilized in mesoporous $\mathrm{TiO}_{2}$ thin films prepared via EISA on custom-made titanium implant fixation screws (Figure 3).

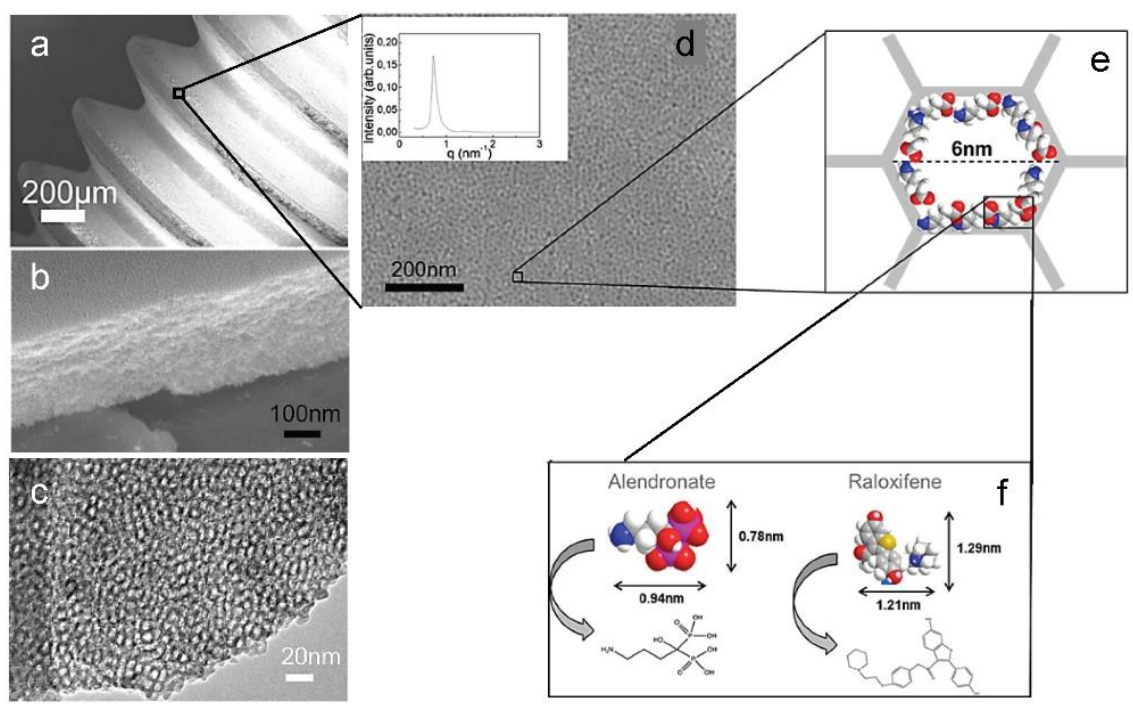

Figure 3. (a) SEM image of a screw-shaped titanium implant coated with a mesoporous $\mathrm{TiO}_{2}$ thin film. (b) Cross section of the mesoporous $\mathrm{TiO}_{2}$ layer. (c) $\mathrm{TEM}$ image of the $\mathrm{TiO}_{2}$ thin film matrix. (d) SEM image of mesoporous implant at a higher magnification; inset shows the synchrotron SAXS pattern for the mesoporous $\mathrm{TiO}_{2}$. The schematic illustration in (e) shows the pore diameter of $6 \mathrm{~nm}$. The active substances ALN and RLX in (f) were absorbed into the porous structure. Adapted from N. Harmankaya et al. Acta Biomaterialia 9 (2013) 7064-7073, with permission from Elsevier.

Due to the different polarity of the two drugs, part of the implants was treated with $1 \%$ dichlorodimethylsilane (DDMS) for $30 \mathrm{~min}$, in order to increase the surface hydrophobicity. The two drugs were then adsorbed to the mesopores, and the prepared implants were characterized via electron microscopy, (SEM TEM), isothermal nitrogen adsorption, diffraction (SAXS, XRD), photoelectron spectroscopy and contact angle to confirm mesoporosity, pore accessibility and hydrophobicity of the surface coating. The adsorption and release of drugs was evaluated by quartz crystal microbalance with dissipation monitoring (QCM-D) [95]. The authors observed that hydrophilic drug Alendronate loading was 30 times more effective with respect to a non-porous surface, while it was only 3 times higher for Raloxifene, which is partially explained by steric interaction of the latter drug and by the higher affinity interaction between the hydrophobic drug and the smooth hydrophobic surface. The effect of loaded and not-loaded implants on bone healing was evaluated on an animal model at 28 days from the implant, considering the mRNA expression of genetic markers for inflammatory and bone remodelling cells (TNF- $\alpha$, Cathepsin $\mathrm{K}$ and Osteocalcin), the bio-mechanical attachment of the implant to the bone, and bone histology. Mesoporous coatings loaded with the two drugs exerted a positive effect on bone regeneration at the implant site and a stronger anchorage to the bone. These results demonstrate the capability of $\mathrm{TiO}_{2}$ mesoporous films as drug release tools, resulting in better implant fixation if compared to those without mesoporous coating.

\section{Antimicrobials}

Recently, the emergence of antibiotic-resistant bacterial infections raised the necessity to develop materials with amtimicrobial effects for applications in the biomedical field. In particular, biocompatible coatings with antibacterial properties are gaining more and more attention from the scientific community involved in the research and development of materials for biotechnology. 
Mesoporous silica and titania thin films are promising tools as coatings to prevent bacterial colonization on surgical implants, thanks to the possibility to load the material with antibiotic drugs coupled with its low adhesive properties for biofilm growth prevention.

In a recently reported experiment, titania thin films prepared via EISA were loaded with gentamicine. The antibiofilm activity was demonstrated by evaluating the growth of $S$. Aureus on the surface of the loaded film. The results demonstrated the antibiofilm activity of the loaded material, and the prolonged release of the antibiotic through the pores.

The surface of the gentamicine-loaded mesoporous thin films was subsequently functionalized with a growth factor (human recombinant bone morphogenetic protein 2, hrBMP-2), in order to couple the antibacterial activity to improved tissue regeneration.

The preosteoblastic cell adhesion and differentiation were tested on the MC3T3-E1 osteoblast precursor cell line, showing the enhanced cell proliferation due to the presence of the growth factor attached to the mesoporous surface [84].

Functionalization with thiol groups allows for loading the mesoporous matrix with peptides or small molecules with antimicrobial activity. Recently, Izquierdo-Barba and collaborators [83] demonstrated the efficacy against bacterial colonization of mesoporous silica surfaces functionalized by co-condensation with 3-mercaptopropyl-trimethoxysilane. The film was subsequently functionalized with the small antimicrobial peptide LL-37, and with the antibacterial drug chlorexidine, and the antibacterial effect against E. Coli and $S$. aureus was tested, and confirmed. Functionalization did not affect the mesoporous arrangement of silica, as demonstrated by XRD measurements, thus preserving the controlled drug delivery capacity of the material. The bactericidal activity was similar after 10 months, demonstrating the stability of the mesoporous material for long-term storage. Moreover, the results showed that functionalization with the -SH group reduced the dissolution of silica in an aqueous environment, while preserving the mesostructure. In comparison with drug-loaded films, those treated with -SH showed slower drug release, demonstrating the possibility of controlling the delivery rate by functionalization.

Atefyekta and colleagues [57] synthesized mesoporous thin films of $\mathrm{TiO}_{2}$ with different structural characteristics, namely 4 to $7 \mathrm{~nm}$ pore size and film thickness from 250 to $700 \mathrm{~nm}$, via EISA on titanium substrates. The deposited films were thermally treated for stabilization and template removal and selected samples were functionalized with dichlorodimethylsilane (DDMS) to increase the surface hydrophobicity and facilitate subsequent loading with low-water soluble drug daptomycin. Further film characterization showed that different pore sizes did not lead to different surface roughness, thus not affecting the anti-adhesive properties of the material. The water-accessible pore volume was evaluated via QCM-D, resulting in increased volume for higher thickness and pore size, as expected if pores are accessible in the whole film. On the other side, DDMS-treated samples showed a slightly lower pore volume, confirming the presence of the functional groups inside the pores.

The treated and non-treated samples were loaded via passive diffusion with daptomycin, vancomycin and gentamicin and used as substrates for bacterial growth, and the antimicrobial activity of the films was tested on S. Aureus and P. Aeruginosa. Both antibiotics loaded and not loaded films could reduce the bacteria adhesion, with enhanced activity in the case of hydrophobic surfaces. Antibiotic loaded material showed increased activity against bacterial film formation, as expected in presence of $7 \mathrm{~nm}$ mesopores. These results demonstrate the effectiveness of mesoporous titania as an antibacterial coating, which can be improved by surface functionalization.

\section{Biofunctionalization}

Enzymes can be encapsulated into mesoporous materials [96] for the production of biosensors and bioreactors, both in co-condensation processes and by adsorption to the condensed material surface. The encapsulated molecules are stable, even in environmental conditions that would normally lead to denaturation [97-99] such as extreme $\mathrm{pH}$ or tem- 
perature, and maintain their activity longer if compared to enzymes free in solution. A disadvantage is that, usually, the sol-gel condensation reaction requires the use of solvents and $\mathrm{pH}$ that would denature or deactivate the enzymes, so the one pot functionalization must be tailored carefully [100]. Thus, post-synthesis functionalization is preferable for these sensitive molecules.

Bellino and colleagues [86] prepared mesoporous silica thin films via EISA. The solution was deposited on glass slides via dip-coating, stabilized overnight at RT in controlled humidity and consolidated via thermal treatment. The obtained film was biofunctionalized with the enzyme $\alpha$-amylase submerging the prepared substrates in enzyme solution under gentle agitation at RT. After $1 \mathrm{~h}$, the excess enzyme was thoroughly rinsed with water and the activity and amount of adsorbed enzyme were evaluated. The authors demonstrated that the mesopores were accessible, that the enzyme was successfully adsorbed, and that it maintained its catalytic activity. To determine the amount of enzyme adsorbed, the pore volume was evaluated via environmental ellipsometric porosimetry (EEP) on non-treated and treated films. The latter showed a decrease in pore dimensions: according to the authors, approximately $4.3 \%$ of the available pore volume is occupied by the adsorbed enzyme, which corresponds to 1 molecule per pore. The starch-iodine colorimetric assay showed that thicker films had a significant capability to degrade starch if compared to non-functionalized silica.

Patterning and subsequent functionalization on the desired region of the mesoporous film is a challenge for the production of biosensing devices: this would allow the creation of microfluidic circuits and arrays of precise geometry, which can be selectively functionalized for the production of biosensors, as demonstrated by Doherty and colleagues [85].

Silica thin films prepared via EISA dip-coating were functionalized by submerging them in a $4.3 \mathrm{mM}$ solution of APTES in toluene, and treated with $1 \%$ glutaraldehyde solution, which enabled to covalently bond the enzyme OpdA to the amino groups. The mesoporosity was confirmed with TEM. By means of an X-ray mask, selected areas of the surface were patterned with Deep X-ray Lithography to remove the functionalization, either before or after the enzyme bonding to the amino-silane. The enzyme presence after lithography was confirmed via FT-IR and its activity on the degradation of an organophosphate compound was tested. Comparison with samples without APTES functionalization demonstrated that the enzyme binding to amino-silane was much more efficient than to not-functionalized $\mathrm{SiO}_{2}$. A similar experiment, conducted binding a luminescent biomarker complex, confirmed the obtained results. In both cases, X-ray irradiation efficiently removed more than $80 \%$ of the bound enzyme, confirming this technique as a versatile tool for selective functionalization of mesoporous materials.

\section{Ions}

Despite the fact that silica substrates undergo biodegradation in in-vivo conditions due to the solubilization of silica matrix and the consequent formation of silicilic acid [19,101], studies have shown that they can be efficiently sterilized and still be used as bioactive coatings, having the advantage of being a source of ions necessary for cell differentiation if submerged in a solution containing inorganic ions similar to body fluid [17]. For instance, Chai and coworkers [88] used $\mathrm{SiO}_{2}$ mesoporous thin films as support for osteoblast-like cell growth. They studied the interaction of mesoporous silica thin films with SBF incubating spin-coated silica for different timing. They evaluated the chemical and structural characteristics of the mesoporous structure via IR spectroscopy to investigate the decay of the Si-O-Si band, X-ray diffraction, AFM to study the surface nanostructure, BET (Brunauer-Emmett-Teller) and BJT (Barrett-Joyner-Halenda) analysis to determine the surface area and the pore size respectively.

The incubation in SBF promoted the adsorption of $\mathrm{Ca}^{2+}, \mathrm{PO}_{4}{ }^{3-}$ and $\mathrm{Mg}^{2+}$ at the mesoporous surface. The positively charged ions at the surface favoured the subsequent binding of fibrinogen, a negatively charged plasma glycoprotein that facilitates cell adhesion and spreading to the surface. After an aggressive sterilization protocol which 
includes calcination, $\mathrm{UV} / \mathrm{O}_{3}$ surface treatment, autoclave and $70 \%$ ethanol washing, the physiochemical characteristics of the SBF-treated mesoporous film were preserved, and they were successfully loaded with fibrinogen. Osteoblast-like MC3T3-E1 cells were grown on the functionalized surface for 14 days, and their differentiation degree after 10 days was evaluated testing the secreted alkaline phosphatase via ALP staining. If compared with standard tissue culture plates, the mesoporous substrate showed higher cytocompatibility and enhanced cell calcification, thus promoting the formation of bone tissue.

Several studies report the capability of mesoporous $\mathrm{TiO}_{2}$ to promote bone cell proliferation when functionalized with bioactive ions. Magnesium, calcium, strontium or zinc are known to promote cell differentiation of bone cell precursors and can be adsorbed on $\mathrm{TiO}_{2}$ mesoporous material [52,53,102-104]. The slow release of these ions from the mesoporous material coated on bone-implant devices such as nails or screws, for instance, promotes better bone mineralization and implant integration.

In a study to examine the implant retention and the healing effect of magnesium on bone, Galli and coworkers deposited thin films of mesoporous $\mathrm{TiO}_{2}$ via spin coating EISA on the surface of commercial threaded titanium implant devices [105]. After overnight stabilization at RT and subsequent thermal treatment to remove the surfactant and consolidate the mesostructure, the coated devices were immersed in an $\mathrm{Mg}^{2+}$ water solution for one hour. The surface of modified implants was extensively characterized with interferometry to evaluate the surface roughness, with SEM to confirm the mesoporosity and with EDX (energy-dispersive $\mathrm{X}$-ray spectroscopy) to evaluate the amount of adsorbed magnesium. The in-vivo model animal study showed that mesoporous coated implants loaded with $\mathrm{Mg}^{2+}$ were better integrated into the healing bone, as demonstrated by the higher removal torque values observed. This suggests that magnesium-loaded mesoporous titania coatings promote bone cell adhesion [106] and better mineralization of newly formed bone at the implant site.

Akgun and collaborators demonstrated that both pure titania thin film, and functionalized $\mathrm{Ag}-\mathrm{TiO}_{2}$ thin films obtained via co-condensation with $\mathrm{AgNO}_{3}$ exhibited bactericidal activity against $S$. Epidermidis, which was enhanced by UV irradiation [107].

The photocatalytic activity of $\mathrm{TiO}_{2}$ when irradiated, can be coupled with the high surface area of $\mathrm{SiO}_{2}$ mesoporous thin films for selective immobilization and long-term release of antimicrobial substances. Catalano and coworkers synthesized hybrid titaniasilica coatings that were loaded with silver [89].

Mesoporous thin films were produced in two steps: the first $\mathrm{TiO}_{2}$ layer was applied to clean microscope glass slides via dip coating. The deposition was followed by $50 \% \mathrm{RH}$ treatment for $24 \mathrm{hr}$ and thermal consolidation. Then, the second layer of $\mathrm{SiO}_{2}$ was deposited again via dip-coating, treated at $50 \% \mathrm{RH}$ for $24 \mathrm{~h}$ and thermally consolidated. The prepared samples were submerged in $0.1 \mathrm{AgNO}_{3}$ water-ethanol solutions and incubated for $1 \mathrm{~h}$. The adsorbed $\mathrm{Ag}^{+}$was quantified calculating the mass fraction of Ag:Ti via EDX. The authors could demonstrate the antimicrobial activity of silver nanoparticles as well as that of silver ions, thanks to the peculiar properties of both mesoporous $\mathrm{TiO}_{2}$ and $\mathrm{SiO}_{2}$. Samples immersed in $\mathrm{AgNO}_{3}$ were either incubated in the dark, or illuminated with a UV lamp: the UV-dependent photocatalytic activity of $\mathrm{TiO}_{2}$ induced in-situ photoreduction of $\mathrm{Ag}^{+}$ ions in the $\mathrm{TiO}_{2}$ layer, thus selectively confining silver nanoparticles in that mesoporous layer and leaving only silver ions in the $\mathrm{SiO}_{2}$ layer mesopores (Figure 4).

They demonstrated that mesoporous hybrid thin films loaded with silver ions, exhibit antimicrobial activity against $S$. Aureus and P. Aeruginosa comparable to that observed in the substrates loaded with Ag nanoparticles, having the advantage that the optical properties of transparent mesoporous coatings are not affected.

To circumvent the difficulties of complexing divalent ions to the mesoporous matrix, and to enhance their adsorption on the mesopores and subsequent slow release, surfacefunctionalized hybrid titania-silica films can be synthesized, coupling carboxylate groups via post-grafting to the surface, as demonstrated by Escobar and colleagues [87]. They produced vinyl-functionalized hybrid titania-silica-thin films and subsequently attached 
carboxylated groups to the surface by click-chemistry. The structure of the mesoporous thin films was characterized with SAXS, XRD and TEM which confirmed the hierarchical order and the porosity of the structure. After being submerged in an $\mathrm{Sr}^{2+}$ aqueous solution for $3 \mathrm{~h}$, the release of ions was assessed at several time intervals, from few minutes to 7 days. Carboxylated films adsorbed double the amount of $\mathrm{Sr}^{2+}$ if compared to non$\mathrm{COOH}$ functionalized films, and showed a more gradual $\mathrm{Sr}^{2+}$ release, demonstrating the effectiveness of surface functionalization for ion complexation. Both types of samples (with and without - $\mathrm{COOH}$ groups attached) were tested for cell viability using MC3T3-E1 pre-osteoblastic cell line from mouse calvaria: the osteoblastic proliferation was quantified, testing the activity of the enzyme alkaline phosphatase which is a well-known marker for osteoblast mineralization [108], and cells adhesion was evaluated with Confocal Laser Scanning Microscopy (CLSM) imaging. Cells grown on non-functionalized mesoporous surfaces showed better adhesion and enhanced proliferation in the first 2 days of culture, indicating the positive effect of $\mathrm{Sr}^{2+}$ fast release on the cell viability. Interestingly, cells cultured on $-\mathrm{COOH}$ functionalized surfaces showed a higher proliferation rate on the third day, and the ALP activity was significantly higher after 15 days of culture, indicating enhanced cell differentiation: in the authors' interpretation, this is the result of the slower $\mathrm{Sr}^{2+}$ release in comparison with non carboxylated mesopores, which might imply a long term positive effect on bone-implant integration.
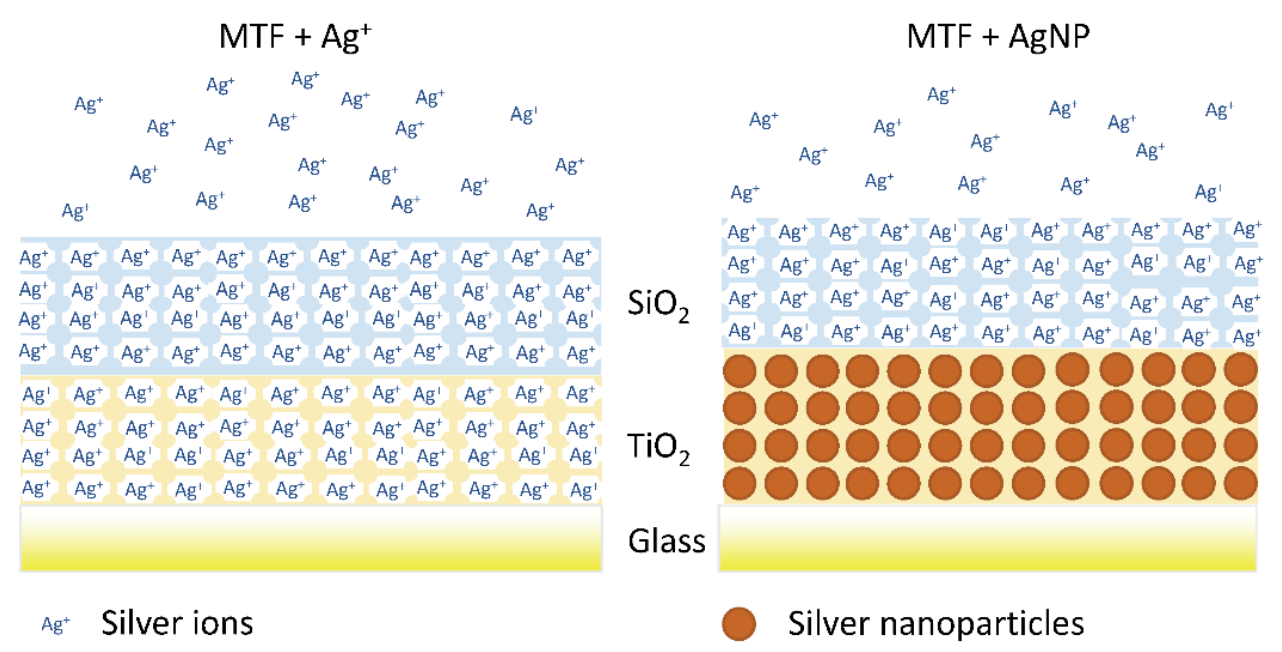

Figure 4. Scheme of the silver loaded silica-titania thin film (left) and of the film with silver nanoparticles embedded in the lower $\mathrm{TiO}_{2}$ layer, covered by the silica layer with $\mathrm{Ag}^{+}$adsorbed (right). Reproduced from P.N. Catalano et al., Microporous and Mesoporous Materials 236 (2016), with permission from Elsevier.

\section{Conclusions}

In this review, we summarized some applications of functionalized mesoporous silica and titania thin films for biotechnology. These innovative materials exhibit remarkable properties, such as antibacterial activities and the stimulation of cell growth, which make them particularly useful for the production of active coatings. Surface modification is the key to new functionalities, because it allows binding to the surface functional groups or molecules with potential therapeutic effects. Functionalization of mesoporous films can enable their use as nanoscaffolds for biotechnological and biomedical applications that range from bioimaging and bioanalysis to diagnosis. The large surface-to-volume ratio makes them ideal hosts for targeting molecules stored in high concentrations.

The objective of mesoporous film functionalization is to combine the pores with multiple functional groups that can be placed at desired locations on the film, and can potentially give rise to synergistic effects on host-guest interactions. Mesoporous thin films are attractive as they can be incorporated into devices and can be tailored with 
respect to both architecture and functionalization. The different porous systems present in hierarchically organized material can be functionalized selectively, which envisages new possibilities for the fabrication of advanced microsensors or devices that combine standard micro/nanofluids with functional materials. The endeavour here is the combination of compatible thin film preparation methods, microfabrication techniques, and functionalization protocols.

Functionalized mesoporous coatings are promising tools for those fields where longterm antibacterial activity or controlled in situ drug delivery is pursued, as well as for the development of sensors based on biologically active molecules such as enzymes.

When surface modification with biological molecules is desired, functionalization protocols might involve solvents or thermal treatment which are harmful to delicate molecules like enzymes: post-synthetic passive diffusion is the method of choice in this case, but this might not be as efficient as chemical coupling of the functional molecule to the mesoporous surface, and is limited by the pores and ligand dimension. A challenge for applications in biotechnology will be the development of functionalization methods that are efficient and at the same time would not harm the ligand. Another task would be to further develop strategies to protect the mesoporous material loaded with therapeutic molecules from degradation in biologically relevant conditions, thus avoiding the uncontrolled release of the loaded drug, or potential risks for the patient due to the matrix degradation.

The application of well-established knowledge on mesoporous thin films combined with experience in functionalization to improve the interaction with biomaterials will allow the design of new applications aimed at the clinical field. The possibility to incorporate multiple active elements in mesoporous thin films will enable tailoring the multifunctional properties to broader ranges of applications.

Author Contributions: Conceptualization, B.M. and B.S.; writing-original draft preparation, B.S., B.M.; writing-review and editing, B.S., B.M., H.A. All authors have read and agreed to the published version of the manuscript.

Funding: This research received no external funding.

Acknowledgments: This work includes part of the scientific activities of the internal CERIC-ERIC project Renewals and of Lead Project Porous Materials at Work 'LEAD-Pj PMW P08'.

Conflicts of Interest: The authors declare no conflict of interest.

\section{References}

1. Soler-Illia, G.J.D.A.A.; Sanchez, C.; Lebeau, B.; Patarin, J. Chemical Strategies To Design Textured Materials: From Microporous and Mesoporous Oxides to Nanonetworks and Hierarchical Structures. Chem. Rev. 2002, 102, 4093-4138. [CrossRef]

2. Sanchez, C.; Arribart, H.; Guille, M.M.G. Biomimetism and bioinspiration as tools for the design of innovative materials and systems. Nat. Mater. 2005, 4, 277-288. [CrossRef] [PubMed]

3. Davis, M.E. Ordered porous materials for emerging applications. Nat. Cell Biol. 2002, 417, 813-821. [CrossRef] [PubMed]

4. Baca, H.K.; Ashley, C.; Carnes, E.; Lopez, D.; Flemming, J.; Dunphy, D.; Singh, S.; Chen, Z.; Liu, N.; Fan, H.; et al. Cell-Directed Assembly of Lipid-Silica Nanostructures Providing Extended Cell Viability. Science 2006, 313, 337-341. [CrossRef] [PubMed]

5. Vallet-Regí, M.; Balas, F. Silica Materials for Medical Applications. Open Biomed. Eng. J. 2008, 2, 1-9. [CrossRef]

6. Vallet-Regí, M. Mesoporous Silica Nanoparticles: Their Projection in Nanomedicine. ISRN Mater. Sci. 2012, 2012, 1-20. [CrossRef]

7. Wu, S.; Weng, Z.; Liu, X.; Yeung, K.W.K.; Chu, P.K. Functionalized TiO2Based Nanomaterials for Biomedical Applications. Adv. Funct. Mater. 2014, 24, 5464-5481. [CrossRef]

8. Wu, S.-H.; Hung, Y.; Mou, C.-Y. Mesoporous silica nanoparticles as nanocarriers. Chem. Commun. 2011, 47, 9972-9985. [CrossRef] [PubMed]

9. Vallet-Regí, M.; Balas, F.; Arcos, D. Mesoporous Materials for Drug Delivery. Angew. Chem. Int. Ed. 2007, 46, 7548-7558. [CrossRef] [PubMed]

10. Sábio, R.M.; Meneguin, A.B.; dos Santos, A.M.; Monteiro, A.S.; Chorilli, M. Exploiting mesoporous silica nanoparticles as versatile drug carriers for several routes of administration. Microporous Mesoporous Mater. 2021, 312, 110774. [CrossRef]

11. Pourshahrestani, S.; Kadri, N.A.; Zeimaran, E.; Towler, M.R. Well-ordered mesoporous silica and bioactive glasses: Promise for improved hemostasis. Biomater. Sci. 2019, 7, 31-50. [CrossRef]

12. Karlsson, J.; Atefyekta, S.; Andersson, M. Controlling drug delivery kinetics from mesoporous titania thin films by pore size and surface energy. Int. J. Nanomed. 2015, 10, 4425-4436. [CrossRef] 
13. Xia, W.; Grandfield, K.; Hoess, A.; Ballo, A.; Cai, Y.; Engqvist, H. Mesoporous titanium dioxide coating for metallic implants. J. Biomed. Mater. Res. Part B Appl. Biomater. 2011, 100, 82-93. [CrossRef] [PubMed]

14. Izquierdo-Barba, I.; Ruiz-González, L.; Doadrio, J.C.; Gonzalez-Calbet, J.M.; Vallet-Regí, M. Tissue regeneration: A new property of mesoporous materials. Solid State Sci. 2005, 7, 983-989. [CrossRef]

15. Peltola, T.; Pätsi, M.; Rahiala, H.; Kangasniemi, I.; Yli-Urpo, A. Calcium phosphate induction by sol-gel-derived titania coatings on titanium substrates in vitro. J. Biomed. Mater. Res. 1998, 41, 504-510. [CrossRef]

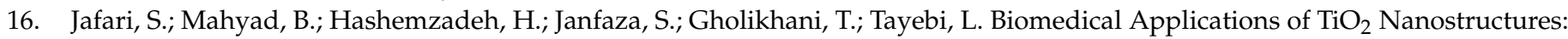
Recent Advances. Int. J. Nanomed. 2020, 15, 3447-3470. [CrossRef]

17. Kokubo, T.; Kushitani, H.; Sakka, S.; Kitsugi, T.; Yamamuro, T. Solutions able to reproduce in vivo surface-structure changes in bioactive glass-ceramic A-W3. J. Biomed. Mater. Res. 1990, 24, 721-734. [CrossRef] [PubMed]

18. Pezzoni, M.; Catalano, P.N.; Pizarro, R.A.; DeSimone, M.F.; Soler-Illia, G.J.; Bellino, M.G.; Costa, C.S. Antibiofilm effect of supramolecularly templated mesoporous silica coatings. Mater. Sci. Eng. C 2017, 77, 1044-1049. [CrossRef] [PubMed]

19. Bindini, E.; Chehadi, Z.; Faustini, M.; Albouy, P.-A.; Grosso, D.; Cattoni, A.; Chanéac, C.; Azzaroni, O.; Sanchez, C.; Boissière, C. Following in Situ the Degradation of Mesoporous Silica in Biorelevant Conditions: At Last, a Good Comprehension of the Structure Influence. ACS Appl. Mater. Interfaces 2020, 12, 13598-13612. [CrossRef]

20. Pezzoni, M.; Catalano, P.N.; Delgado, D.C.; Pizarro, R.A.; Bellino, M.G.; Costa, C.S. Antibiofilm effect of mesoporous titania coatings on Pseudomonas aeruginosa biofilms. J. Photochem. Photobiol. B Biol. 2020, 203, 111762. [CrossRef] [PubMed]

21. Kresge, C.T.; Leonowicz, M.E.; Roth, W.; Vartuli, J.C.; Beck, J.S. Ordered mesoporous molecular sieves synthesized by a liquid-crystal template mechanism. Nat. Cell Biol. 1992, 359, 710-712. [CrossRef]

22. David, M.; Antonelli, J.Y.Y. Synthesis of Hexagonally Packed Mesoporous TiO2 by a Modified Sol-Gel Method. Angew. Chemie Int. Ed. Engl. 1995, 34, 2014-2017.

23. Kumar, S.; Malik, M.; Purohit, R. Synthesis Methods of Mesoporous Silica Materials. Mater. Today Proc. 2017, 4, 350-357. [CrossRef]

24. Zhang, W.; Tian, Y.; He, H.; Xu, L.; Li, W.; Zhao, D. Recent advances in the synthesis of hierarchically mesoporous TiO2 materials for energy and environmental applications. Natl. Sci. Rev. 2020, 7, 1702-1725. [CrossRef]

25. Huang, R.; Shen, Y.-W.; Guan, Y.-Y.; Jiang, Y.-X.; Wu, Y.; Rahman, K.; Zhang, L.-J.; Liu, H.-J.; Luan, X. Mesoporous silica nanoparticles: Facile surface functionalization and versatile biomedical applications in oncology. Acta Biomater. 2020, 116, 1-15. [CrossRef] [PubMed]

26. Stöber, W.; Fink, A.; Bohn, E. Controlled growth of monodisperse silica spheres in the micron size range. J. Colloid Interface Sci. 1968, 26, 62-69. [CrossRef]

27. Brinker, C.J.; Scherer, G.W. Sol-Gel Science the Physics and Chemistry of Sol-Gel Processing; Academic Press, I., Ed.; Elsevier B.V.: Amsterdam, The Netherlands, 1990.

28. Brinker, C.J.; Lu, Y.; Sellinger, A.; Fan, H. Evaporation-Induced Self-Assembly: Nanostructures Made Easy. Adv. Mater. 1999, 11, 579-585. [CrossRef]

29. Velev, O.; Jede, T.A.; Lobo, R.F.; Lenhoff, A. Porous silica via colloidal crystallization. Nat. Cell Biol. 1997, 389, 447-448. [CrossRef]

30. Holland, B.T.; Blanford, C.F.; Stein, A. Synthesis of Macroporous Minerals with Highly Ordered Three-Dimensional Arrays of Spheroidal Voids. Science 1998, 281, 538-540. [CrossRef] [PubMed]

31. Yang, P.; Deng, T.; Zhao, D.; Feng, P.; Pine, D.; Chmelka, B.F.; Whitesides, G.M.; Stucky, G.D. Hierarchically Ordered Oxides. Science 1998, 282, 2244-2246. [CrossRef]

32. Mahoney, L.; Koodali, R. Versatility of Evaporation-Induced Self-Assembly (EISA) Method for Preparation of Mesoporous TiO2 for Energy and Environmental Applications. Materials 2014, 7, 2697-2746. [CrossRef] [PubMed]

33. Grosso, D.; Balkenende, A.R.; Albouy, P.A.; Lavergne, M.; Mazerolles, L.; Babonneau, F. Highly oriented 3D-hexagonal silica thin films produced with cetyltrimethylammonium bromide. J. Mater. Chem. 2000, 10, 2085-2089. [CrossRef]

34. Soler-Illia, G.J.A.A.; Angelomé, P.; Fuertes, M.C.; Grosso, D.; Boissiere, C. Critical aspects in the production of periodically ordered mesoporous titania thin films. Nanoscale 2012, 4, 2549-2566. [CrossRef]

35. Lionello, D.F.; Steinberg, P.Y.; Zalduendo, M.; Soler-Illia, G.J.A.A.; Angelomé, P.C.; Fuertes, M.C. Structural and Mechanical Evolution of Mesoporous Films with Thermal Treatment: The Case of Brij 58 Templated Titania. J. Phys. Chem. C 2017, 121, 22576-22586. [CrossRef]

36. Innocenzi, P.; Malfatti, L.; Falcaro, P. Hard X-rays meet soft matter: When bottom-up and top-down get along well. Soft Matter 2012, 8, 3722-3729. [CrossRef]

37. Schwenzer, B.; Wang, L.; Swensen, J.S.; Padmaperuma, A.B.; Silverman, G.; Korotkov, R.; Gaspar, D.J. Tuning the Optical Properties of Mesoporous TiO2 Films by Nanoscale Engineering. Langmuir 2012, 28, 10072-10081. [CrossRef]

38. Giménez, G.; Ybarra, G.; Soler-Illia, G.J.A.A. Preparation of mesoporous silica thin films at low temperature: A comparison of mild structure consolidation and template extraction procedures. J. Sol-Gel Sci. Technol. 2020, 96, 287-296. [CrossRef]

39. Solveyra, E.G.; Fuertes, M.C.; Soler-Illia, G.J.A.A.; Angelomé, P.C. 2D-SAXS In Situ Measurements as a Tool To Study Elusive Mesoporous Phases: The Case of p6mm TiO2. J. Phys. Chem. C 2017, 121, 3623-3631. [CrossRef]

40. Chemin, N.; Klotz, M.; Rouessac, V.; Ayral, A.; Barthel, E. Mechanical properties of mesoporous silica thin films: Effect of the surfactant removal processes. Thin Solid Films 2006, 495, 210-213. [CrossRef] 
41. Imai, H.; Hirashima, H.; Awazu, K. Alternative modification methods for sol-gel coatings of silica, titania and silica-titania using ultraviolet irradiation and water vapor. Thin Solid Films 1999, 351, 91-94. [CrossRef]

42. Doshi, D.A.; Huesing, N.K.; Lu, M.; Fan, H.; Lu, Y.; Simmons-Potter, K., Jr.; Hurd, A.J.; Brinker, C.J. Optically Defined Multifunctional Patterning of Photosensitive Thin-Film Silica Mesophases. Science 2000, 290, 107-111. [CrossRef]

43. Dattelbaum, A.M.; Amweg, M.L.; Ecke, L.E.; Yee, C.K.; Shreve, A.P.; Parikh, A.N. Photochemical Pattern Transfer and Enhancement of Thin Film Silica Mesophases. Nano Lett. 2003, 3, 719-722. [CrossRef]

44. Della Giustina, G.; Prasciolu, M.; Brusatin, G.; Guglielmi, M.; Romanato, F. Electron beam lithography of hybrid sol-gel negative resist. Microelectron. Eng. 2009, 86, 745-748. [CrossRef]

45. Marmiroli, B.; Amenitsch, H. X-ray lithography and small-angle X-ray scattering: A combination of techniques merging biology and materials science. Eur. Biophys. J. 2012, 41, 851-861. [CrossRef] [PubMed]

46. Innocenzi, P.; Malfatti, L.; Marmiroli, B.; Falcaro, P. Hard X-rays and soft-matter: Processing of sol-gel films from a top down route. J. Sol-Gel Sci. Technol. 2014, 70, 236-244. [CrossRef]

47. Covarrubias, C.; Mattmann, M.; Von Marttens, A.; Caviedes, P.; Arriagada, C.; Valenzuela, F.; Rodríguez, J.P.; Corral, C. Osseointegration properties of titanium dental implants modified with a nanostructured coating based on ordered porous silica and bioactive glass nanoparticles. Appl. Surf. Sci. 2016, 363, 286-295. [CrossRef]

48. Park, S.W.; Lee, D.; Choi, Y.S.; Jeon, H.B.; Lee, C.-H.; Moon, J.-H.; Kwon, I.K. Mesoporous TiO2 implants for loading high dosage of antibacterial agent. Appl. Surf. Sci. 2014, 303, 140-146. [CrossRef]

49. Wu, P.-H.; Mäkie, P.; Odén, M.; Björk, E.M. Growth and Functionalization of Particle-Based Mesoporous Silica Films and Their Usage in Catalysis. Nanomaterials 2019, 9, 562. [CrossRef]

50. Caricato, A.; Arima, V.; Catalano, M.; Cesaria, M.; Cozzoli, P.; Martino, M.; Taurino, A.; Rella, R.; Scarfiello, R.; Tunno, T.; et al. MAPLE deposition of nanomaterials. Appl. Surf. Sci. 2014, 302, 92-98. [CrossRef]

51. Rădulescu, D.; Voicu, G.; Oprea, A.E.; Andronescu, E.; Grumezescu, V.; Holban, A.M.; Vasile, B.S.; Surdu, V.-A.; Grumezescu, A.M.; Socol, G.; et al. Mesoporous silica coatings for cephalosporin active release at the bone-implant interface. Appl. Surf. Sci. 2016, 374, 165-171. [CrossRef]

52. Galli, S.; Naito, Y.; Karlsson, J.; He, W.; Miyamoto, I.; Xue, Y.; Andersson, M.; Mustafa, K.; Wennerberg, A.; Jimbo, R. Local release of magnesium from mesoporous TiO 2 coatings stimulates the peri-implant expression of osteogenic markers and improves osteoconductivity in vivo. Acta Biomater. 2014, 10, 5193-5201. [CrossRef]

53. Grandfield, K.; Pujari, S.; Ott, M.; Engqvist, H.; Xia, W. Effect of Calcium and Strontium on Mesoporous Titania Coatings for Implant Applications. J. Biomater. Nanobiotechnol. 2013, 04, 107-113. [CrossRef]

54. Björk, E.M.; Baumann, B.; Hausladen, F.; Wittig, R.; Lindén, M. Cell adherence and drug delivery from particle based mesoporous silica films. RSC Adv. 2019, 9, 17745-17753. [CrossRef]

55. Solano-Umaña, V.; Vega-Baudrit, J.R. Micro, Meso and Macro Porous Materials on Medicine. J. Biomater. Nanobiotechnol. 2015, 6, 247-256. [CrossRef]

56. Gentile, F.; La Rocca, R.; Marinaro, G.; Nicastri, A.; Toma, A.; Paonessa, F.; Cojoc, G.; Liberale, C.; Benfenati, F.; Di Fabrizio, E.; et al. Differential Cell Adhesion on Mesoporous Silicon Substrates. ACS Appl. Mater. Interfaces 2012, 4, 2903-2911. [CrossRef] [PubMed]

57. Andersson, M.; Atefyekta, S.; Ercan, B.; Karlsson, J.; Taylor, E.; Chung, S.; Webster, T.J. Antimicrobial performance of mesoporous titania thin films: Role of pore size, hydrophobicity, and antibiotic release. Int. J. Nanomed. 2016, 11, 977-990. [CrossRef] [PubMed]

58. Campoccia, D.; Montanaro, L.; Arciola, C.R. A review of the biomaterials technologies for infection-resistant surfaces. Biomaterials 2013, 34, 8533-8554. [CrossRef]

59. Visai, L.; De Nardo, L.; Punta, C.; Melone, L.; Cigada, A.; Imbriani, M.; Arciola, C.R. Titanium Oxide Antibacterial Surfaces in Biomedical Devices. Int. J. Artif. Organs 2011, 34, 929-946. [CrossRef]

60. Kumaravel, V.; Nair, K.M.; Mathew, S.; Bartlett, J.; Kennedy, J.E.; Manning, H.G.; Whelan, B.J.; Leyland, N.S.; Pillai, S.C. Antimicrobial TiO2 nanocomposite coatings for surfaces, dental and orthopaedic implants. Chem. Eng. J. $2021,416,129071$. [CrossRef]

61. Innocenzi, P.; Malfatti, L. Mesoporous thin films: Properties and applications. Chem. Soc. Rev. 2013, 42, 4198-4216. [CrossRef]

62. Kumar, M.N.V.R.; Sameti, M.; Mohapatra, S.; Kong, X.; Lockey, R.; Bakowsky, U.; Lindenblatt, G.; Schmidt, C.H.; Lehr, C.-M. Cationic Silica Nanoparticles as Gene Carriers: Synthesis, Characterization and Transfection Efficiency In vitro and In vivo. J. Nanosci. Nanotechnol. 2004, 4, 876-881. [CrossRef]

63. Jung, J.-I.; Bae, J.Y.; Bae, B.-S. Characterization and mesostructure control of mesoporous fluorinated organosilicate films. J. Mater. Chem. 2004, 14, 1988-1994. [CrossRef]

64. Hu, T.; Bouamrani, A.; Tasciotti, E.; Li, L.; Liu, X.; Ferrari, M. Tailoring of the Nanotexture of Mesoporous Silica Films and Their Functionalized Derivatives for Selectively Harvesting Low Molecular Weight Protein. ACS Nano 2009, 4, 439-451. [CrossRef]

65. Boullanger, A.; Alauzun, J.; Mehdi, A.; Reyé, C.; Corriu, R.J.P. Generic way for functionalised well-ordered cubic mesoporous silica via direct synthesis approach. New J. Chem. 2010, 34, 738-743. [CrossRef]

66. Bass, J.D.; Grosso, D.; Boissiere, C.; Belamie, E.; Coradin, A.T.; Sanchez, C. Stability of Mesoporous Oxide and Mixed Metal Oxide Materials under Biologically Relevant Conditions. Chem. Mater. 2007, 19, 4349-4356. [CrossRef]

67. He, Q.; Zhang, J.; Shi, J.; Zhu, Z.; Zhang, L.; Bu, W.; Guo, L.; Chen, Y. The effect of PEGylation of mesoporous silica nanoparticles on nonspecific binding of serum proteins and cellular responses. Biomaterials 2010, 31, 1085-1092. [CrossRef] [PubMed] 
68. Park, S.S.; Ha, C.-S. Organic-inorganic hybrid mesoporous silicas: Functionalization, pore size, and morphology control. Chem. Rec. 2006, 6, 32-42. [CrossRef] [PubMed]

69. Tamanna, T.; Cashin, V.; Landersdorfer, C.B.; Bulitta, J.B.; Yu, A. Stability and controlled antibiotic release from thin films embedded with antibiotic loaded mesoporous silica nanoparticles. RSC Adv. 2015, 5, 107839-107846. [CrossRef]

70. Pérez-Anguiano, O.; Wenger, B.; Pugin, R.; Hofmann, H.; Scolan, E. Controlling Mesopore Size and Processability of Transparent Enzyme-Loaded Silica Films for Biosensing Applications. ACS Appl. Mater. Interfaces 2015, 7, 2960-2971. [CrossRef] [PubMed]

71. Magner, E. Immobilisation of enzymes on mesoporous silicate materials. Chem. Soc. Rev. 2013, 42, 6213-6222. [CrossRef]

72. Soler-Illia, G.J.A.A.; Innocenzi, P. Mesoporous Hybrid Thin Films: The Physics and Chemistry Beneath. Chem. A Eur. J. 2006, 12, 4478-4494. [CrossRef] [PubMed]

73. Escobar, A.; Yate, L.; Grzelczak, M.; Amenitsch, H.; Moya, S.E.; Bordoni, A.V.; Angelomé, P.C. One-Step Synthesis of Mesoporous Silica Thin Films Containing Available COOH Groups. ACS Omega 2017, 2, 4548-4555. [CrossRef] [PubMed]

74. Athens, G.L.; Shayib, R.M.; Chmelka, B.F. Functionalization of mesostructured inorganic-organic and porous inorganic materials. Curr. Opin. Colloid Interface Sci. 2009, 14, 281-292. [CrossRef]

75. Calvo, A.; Joselevich, M.; Soler-Illia, G.J.; Williams, F.J. Chemical reactivity of amino-functionalized mesoporous silica thin films obtained by co-condensation and post-grafting routes. Microporous Mesoporous Mater. 2009, 121, 67-72. [CrossRef]

76. Bellino, M.G.; Tropper, I.; Durán, H.; Regazzoni, A.E.; Soler-Illia, G.J.A.A. Polymerase-Functionalized Hierarchical Mesoporous Titania Thin Films: Towards a Nanoreactor Platform for DNA Amplification. Small 2010, 6, 1221-1225. [CrossRef] [PubMed]

77. Tiemann, M.; Weinberger, C. Selective Modification of Hierarchical Pores and Surfaces in Nanoporous Materials. Adv. Mater. Interfaces 2021, 8, 1-17. [CrossRef]

78. Marmiroli, B.; Sartori, B.; Kyvik, A.; Ratera, I.A.H. Structural study of the hydration of lipid membranes upon interaction with mesoporous supports prepared by standard methods and/or X-ray irradiation. Front. Mater. Sect. Colloid. Mater. Interfaces 2021 submitted.

79. Nicole, L.; Boissière, C.; Grosso, D.; Quach, A.; Sanchez, C. Mesostructured hybrid organic-inorganic thin films. J. Mater. Chem. 2005, 15, 3598-3627. [CrossRef]

80. Khalil, A.; Zimmermann, M.; Bell, A.K.; Kunz, U.; Hardt, S.; Kleebe, H.-J.; Stark, R.W.; Stephan, P.; Andrieu-Brunsen, A. Insights into the interplay of wetting and transport in mesoporous silica films. J. Colloid Interface Sci. 2020, 560, 369-378. [CrossRef]

81. Fontecave, T.; Sanchez, C.; Azaïs, T.; Boissière, C. Chemical Modification As a Versatile Tool for Tuning Stability of Silica Based Mesoporous Carriers in Biologically Relevant Conditions. Chem. Mater. 2012, 24, 4326-4336. [CrossRef]

82. Harmankaya, N.; Karlsson, J.; Palmquist, A.; Halvarsson, M.; Igawa, K.; Andersson, M.; Tengvall, P. Raloxifene and alendronate containing thin mesoporous titanium oxide films improve implant fixation to bone. Acta Biomater. 2013, 9, 7064-7073. [CrossRef] [PubMed]

83. Izquierdo-Barba, I.; Vallet-Regí, M.; Kupferschmidt, N.; Terasaki, O.; Schmidtchen, A.; Malmsten, M. Incorporation of antimicrobial compounds in mesoporous silica film monolith. Biomaterials 2009, 30, 5729-5736. [CrossRef]

84. Escobar, A.; Muzzio, N.; Coy, E.; Liu, H.; Bindini, E.; Andreozzi, P.; Wang, G.; Angelomé, P.; Delcea, M.; Grzelczak, M.; et al. Antibacterial Mesoporous Titania Films with Embedded Gentamicin and Surface Modified with Bone Morphogenetic Protein 2 to Promote Osseointegration in Bone Implants. Adv. Mater. Interfaces 2019, 6, 1-12. [CrossRef]

85. Doherty, C.M.; Gao, Y.; Marmiroli, B.; Amenitsch, H.; Lisi, F.; Malfatti, L.; Okada, K.; Takahashi, M.; Hill, A.J.; Innocenzi, P.; et al. Microfabrication of mesoporous silica encapsulated enzymes using deep X-ray lithography. J. Mater. Chem. 2012, 22, 16191-16195. [CrossRef]

86. Bellino, M.G.; Regazzoni, A.E.; Soler-Illia, G.J.A.A. Amylase-Functionalized Mesoporous Silica Thin Films as Robust Biocatalyst Platforms. ACS Appl. Mater. Interfaces 2010, 2, 360-365. [CrossRef]

87. Escobar, A.; Muzzio, N.E.; Martínez-Villacorta, Á.M.; Abarrategi, A.; Bindini, E.; Grzelczak, M.; Bordoni, A.V.; Angelomé, P.; Moya, S.E. Mesoporous titania coatings with carboxylated pores for complexation and slow delivery of strontium for osteogenic induction. Appl. Surf. Sci. 2020, 510, 145172. [CrossRef]

88. Chai, Y.; Yamada, S.; Kobayashi, K.; Hasegawa, K.; Tagaya, M. Surface-functionalization of mesoporous silica films for effective osteoblast-like cell culture. Microporous Mesoporous Mater. 2019, 286, 1-8. [CrossRef]

89. Catalano, P.N.; Pezzoni, M.; Costa, C.; Soler-Illia, G.J.D.A.A.; Bellino, M.G.; Desimone, M.F. Optically transparent silver-loaded mesoporous thin film coating with long-lasting antibacterial activity. Microporous Mesoporous Mater. 2016, 236, 158-166. [CrossRef]

90. Trindade, F.; Politi, M.J. Sol-Gel Chemistry-Deals with Sol-Gel Processes; Elsevier Inc.: Amsterdam, The Netherlands, 2019.

91. Paris, J.L.; Cabañas, M.V.; Manzano, M.; Vallet-Regí, M. Polymer-Grafted Mesoporous Silica Nanoparticles as UltrasoundResponsive Drug Carriers. ACS Nano 2015, 9, 11023-11033. [CrossRef]

92. Rosenholm, J.; Sahlgren, C.C.; Lindén, M. Towards multifunctional, targeted drug delivery systems using mesoporous silica nanoparticles-opportunities \& challenges. Nanoscale 2010, 2, 1870-1883. [CrossRef]

93. De Jong, W.H.; Borm, P.J. Drug delivery and nanoparticles:applications and hazards. Int. J. Nanomed. 2008, 3, 133-149. [CrossRef] [PubMed]

94. Björk, E.M.; Söderlind, F.; Odén, M. Single-pot synthesis of ordered mesoporous silica films with unique controllable morphology. J. Colloid Interface Sci. 2014, 413, 1-7. [CrossRef] [PubMed]

95. Tonda-Turo, C.; Carmagnola, I.; Ciardelli, G. Quartz Crystal Microbalance With Dissipation Monitoring: A Powerful Method to Predict the in vivo Behavior of Bioengineered Surfaces. Front. Bioeng. Biotechnol. 2018, 6, 158. [CrossRef] [PubMed] 
96. Jahnke, J.P.; Idso, M.N.; Hussain, S.; Junk, M.J.N.; Fisher, J.M.; Phan, D.D.; Han, S.; Chmelka, B.F. Functionally Active Membrane Proteins Incorporated in Mesostructured Silica Films. J. Am. Chem. Soc. 2018, 140, 3892-3906. [CrossRef]

97. Lee, C.-H.; Lin, T.-S.; Mou, C.-Y. Mesoporous materials for encapsulating enzymes. Nano Today 2009, 4, 165-179. [CrossRef]

98. Kuo, P.-C.; Lin, Z.-X.; Wu, T.-Y.; Hsu, C.-H.; Lin, H.-P.; Wu, T.-S. Effects of morphology and pore size of mesoporous silicas on the efficiency of an immobilized enzyme. RSC Adv. 2021, 11, 10010-10017. [CrossRef]

99. Frančič, N.; Bellino, M.G.; Soler-Illia, G.J.A.A.; Lobnik, A. Mesoporous titania thin films as efficient enzyme carriers for paraoxon determination/detoxification: Effects of enzyme binding and pore hierarchy on the biocatalyst activity and reusability. Analyst 2014, 139, 3127-3136. [CrossRef] [PubMed]

100. Avnir, D.; Coradin, T.; Lev, O.; Livage, J. Recent bio-applications of sol-gel materials. J. Mater. Chem. 2006, 16, 1013-1030. [CrossRef]

101. Chen, Y.; Chen, H.; Shi, J. In Vivo Bio-Safety Evaluations and Diagnostic/Therapeutic Applications of Chemically Designed Mesoporous Silica Nanoparticles. Adv. Mater. 2013, 25, 3144-3176. [CrossRef]

102. Zhang, W.; Cao, H.; Zhang, X.; Li, G.; Chang, Q.; Zhao, J.; Qiao, Y.; Ding, X.; Yang, G.; Liu, X.; et al. A strontium-incorporated nanoporous titanium implant surface for rapid osseointegration. Nanoscale 2016, 8, 5291-5301. [CrossRef]

103. Yoshizawa-Smith, S.; Brown, A.; Barchowsky, A.; Sfeir, C. Magnesium ion stimulation of bone marrow stromal cells enhances osteogenic activity, simulating the effect of magnesium alloy degradation. Acta Biomater. 2014, 10, 2834-2842. [CrossRef] [PubMed]

104. Lim, S.S.; Chai, C.Y.; Loh, H.-S. In vitro evaluation of osteoblast adhesion, proliferation and differentiation on chitosan-TiO2 nanotubes scaffolds with Ca2+ ions. Mater. Sci. Eng. C 2017, 76, 144-152. [CrossRef]

105. Galli, S.; Naito, Y.; Karlsson, J.; He, W.; Andersson, M.; Wennerberg, A.; Jimbo, R. Osteoconductive Potential of Mesoporous Titania Implant Surfaces Loaded with Magnesium: An Experimental Study in the Rabbit. Clin. Implant Dent. Relat. Res. 2015, 17, 1048-1059. [CrossRef] [PubMed]

106. Park, J.-W.; Kim, Y.-J.; Jang, J.-H. Enhanced osteoblast response to hydrophilic strontium and/or phosphate ions-incorporated titanium oxide surfaces. Clin. Oral Implant. Res. 2010, 21, 398-408. [CrossRef]

107. Akgun, B.A.; Wren, A.W.; Durucan, C.; Towler, M.R.; Mellott, N.P. Sol-gel derived silver-incorporated titania thin films on glass: Bactericidal and photocatalytic activity. J. Sol-Gel Sci. Technol. 2011, 59, 228-238. [CrossRef]

108. Zernik, J.; Twarog, K.; Upholt, W.B. Regulation of alkaline phosphatase and alpha2(I) procollagen synthesis during early intramembranous bone formation in the rat mandible. Differentiation 1990, 44, 207-215. [CrossRef] [PubMed] 